\title{
Relative efficacy of interventions in the treatment of second-line non-small cell lung cancer: a systematic review and network meta-analysis
}

Adrian D. Vickers ${ }^{1 *}$ (D, Katherine B. Winfree ${ }^{2}$, Gebra Cuyun Carter ${ }^{2}$, Urpo Kiiskinen ${ }^{3}$, Min-Hua Jen ${ }^{4}$, Donald Stull, James A. Kaye ${ }^{6}$ and David P. Carbone ${ }^{7}$

\begin{abstract}
Background: Locally advanced or metastatic non-small cell lung cancer (NSCLC) that has progressed after first-line treatment has a poor prognosis. Recent randomized clinical trials (RCTs) have demonstrated survival benefits of alternative treatments to docetaxel. However, information is lacking on which patients benefit the most and what drug or regimen is optimal. We report a systematic review and network meta-analysis (NMA) of second-line treatments in all subgroup combinations determined by histology, programmed death ligand 1 (PD-L1) expression, and epidermal growth factor receptor (EGFR) mutation.
\end{abstract}

Methods: MEDLINE, PubMed, EMBASE, Biosciences Information Service (using the Dialog Platform), Cochrane Library, and abstracts from scientific meetings were searched for RCTs published up to September 2015. Key outcomes were overall survival (OS) and progression-free survival (PFS). Bayesian hierarchical exchangeable NMAs were conducted to calculate mean survival times and relative differences for eight subgroups, using docetaxel as the reference comparator. For OS, the NMA was based on hazard ratios applied to a first-order fractional polynomial model fitted to the reference treatment. For PFS, a second-order fractional polynomial model was fitted to reconstructed patient-level data for the entire network of evidence.

Results: The search identified 30 studies containing 17 different treatment regimens. Docetaxel plus ramucirumab was associated with a significant improvement in OS and PFS, relative to docetaxel, regardless of patient type. Docetaxel plus nintedanib showed similar efficacy to docetaxel plus ramucirumab in the nonsquamous populations. EGFR tyrosine kinase inhibitors (TKls) erlotinib and gefitinib showed superior levels of efficacy in EGFR mutation-positive populations and the one PD-1 immunotherapy (nivolumab) studied showed superior efficacy in the populations exhibiting high PD-L1 expression.

Conclusions: In the absence of head-to-head comparisons, we performed a mixed-treatment analysis to synthesize evidence of the efficacy of each treatment. Benefits are optimized by targeting specific treatments to individual patients guided by histology, PD-L1 expression, and EGFR mutation status.

Systematic review registration: This review is registered in PROSPERO (registration number: CRD42014013780 available at www.crd.york.ac.uk/PROSPERO).

Keywords: Advanced/metastatic non-small cell lung cancer, Chemotherapy, Randomized clinical trials, Histology, PD-L1, TKI, EGFR, Systematic review, Network meta-analysis

\footnotetext{
* Correspondence: avickers@rti.org

${ }^{1}$ RTI Health Solutions, The Pavilion, Towers Business Park, Wilmslow Road,

Didsbury, Manchester M20 2LS, UK

Full list of author information is available at the end of the article
}

(c) The Author(s). 2019 Open Access This article is distributed under the terms of the Creative Commons Attribution 4.0 International License (http://creativecommons.org/licenses/by/4.0/), which permits unrestricted use, distribution, and reproduction in any medium, provided you give appropriate credit to the original author(s) and the source, provide a link to the Creative Commons license, and indicate if changes were made. The Creative Commons Public Domain Dedication waiver (http://creativecommons.org/publicdomain/zero/1.0/) applies to the data made available in this article, unless otherwise stated. 


\section{Background}

Lung cancer is the most commonly occurring life-threatening cancer in the world, with an estimated 1.8 million new cases diagnosed in 2012 (12.9\% of all new cancers) [1]. Lung cancer is estimated to be the leading cause of cancer-related deaths in men in Europe (25\% of all cancer-related deaths) and represents the second most common cause of cancer-related deaths in women in Europe (14\% of all cancer-related deaths) [2]. In the United States, lung cancer is the leading cause of cancer-related deaths in both men and women (26\% of all cancer-related deaths) [3]. Approximately $85 \%$ of newly diagnosed cases are classified as non-small cell lung cancer (NSCLC), while the remaining 10 to $15 \%$ are small cell lung cancer and fewer than $5 \%$ are lung carcinoid tumors [4]. NSCLC includes squamous cell carcinoma (approximately $30 \%$ of all lung cancers), adenocarcinoma (approximately 30-40\% of all lung cancers), and large cell carcinoma (approximately $10-15 \%$ of all lung cancers) [5]. Because symptoms of the disease are nonspecific (e.g., cough, dyspnea, fatigue, weight loss) or absent, approximately $65 \%$ of patients globally present with advanced-stage disease (i.e., stage IIIB or stage IV) [5, 6].

The natural history of untreated advanced NSCLC is poor, with a median survival of 2 to 5 months from diagnosis [7]. In the first-line treatment setting, due to the introduction of new drugs and patient selection based on histological subtypes and driver mutations that influence the biology of these malignancies, the median survival for patients with advanced NSCLC receiving platinum-based chemotherapy in combination with agents targeting specific histologies and mutations has improved to 12 months or longer in randomized controlled trial populations [8]. However, despite the availability of multiple treatment options in the second-line setting, clinical outcomes remain poor. Response rates are, on average, less than $10 \%$, and median survival is 7 to 9 months from the start of second-line therapy [9]. Only a fraction of patients diagnosed with this disease are alive and fit for trials of second-line therapy.

A number of novel agents targeting specific pathways associated with apoptosis, cell proliferation, angiogenesis, and other antineoplastic mechanisms have recently emerged. This research has led to the regulatory approval of regimens that offer improved clinical outcomes for patients with NSCLC, and these regimens are now reflected in current guidelines from the National Comprehensive Cancer Network in the United States [10] and from the European Society for Medical Oncology in Europe [11].

The inclusion of information on biomarkers such as epidermal growth factor receptor (EGFR) mutations and programmed death ligand 1 (PD-L1) expression in clinical trials and the evidence of how particular interventions behave according to tumor histology means that the evidence base in NSCLC is becoming increasingly complex. Previous meta-analytic studies have tended to either focus on the entire population such as Jansen [12], only one subgroup (adenocarcinoma; Popat et al. [13]), or have split the evidence base into subgroups such as the Institute for Clinical and Economic Review [14] (tyrosine kinase inhibitors [TKIs] and programmed death 1 [PD-1] immunotherapies) and Liang et al. [15] (TKIs in EGFR mutation populations). However, one network meta-analysis (NMA) on maintenance treatments was conducted using a hierarchical model with covariates for EGFR mutation, histology, and response to previous induction [16], and a study by Vale et al. [17] investigated the efficacy of TKIs with EGFR status. A range of different models also have been used to fit NMAs in NSCLC. Jansen [12] used fractional polynomials, the Institute for Clinical and Economic Review [14] used hazard ratio and parametric survival models (Weibull and Gompertz), and the remainder have relied on hazard ratios.

The aim of this study was to provide comprehensive evidence on the efficacy of available second-line treatment options for patients with advanced NSCLC of clinically meaningful subtypes defined by histology, PD-L1 expression, and EGFR mutation. For this purpose, we conducted an NMA with Bayesian hierarchical exchangeable structures which allow treatment effects to vary by covariates representing these subtypes.

\section{Methods}

\section{Systematic literature review}

A systematic literature review was undertaken to identify all relevant publications of phase $2 / 3$ randomized controlled trials that were conducted in adult patients who had locally advanced or metastatic NSCLC and whose disease had progressed after first-line chemotherapy through 2 September 2015. There were no date, language, or geographical restrictions on the medical reference database searches. The search strategy involved searches of MEDLINE (using PubMed platform), MEDLINE In-Process (using PubMed platform), Embase (using Elsevier platform), Biosciences Information Service (using the Dialog Platform) and the Cochrane Library (using the Wiley platform). Additionally, the American Society of Clinical Oncology, the European Society of Medical Oncology, and the International Association for the Study of Lung Cancer were searched for relevant new evidence. The search included regimens containing the following interventions: docetaxel (any dose), erlotinib (150 mg), gefitinib (250 mg), gemcitabine (any dose), nintedanib (200 mg), nivolumab (3 mg/kg), pembrolizumab (any dose), pemetrexed (500 $\left.\mathrm{mg} / \mathrm{m}^{2}\right)$, ramucirumab $(10 \mathrm{mg} / \mathrm{kg})$, vinorelbine (any dose), and best supportive care. Two further interventions also were included from this literature review due to growing interest in the Asian market. These were S-1 $\left(40 \mathrm{mg} / \mathrm{m}^{2}\right)$ and bevacizumab $(15 \mathrm{mg} / \mathrm{kg})$. After the systematic literature review had been completed, the trial results for 
pembrolizumab [18] were published online in December 2015 and made fully available in April 2016. That study was considered in addition to the 30 clinical trials identified for inclusion in the NMA.

Two independent reviewers performed the screening; where there was any uncertainty about inclusion, the study was checked by a third researcher. Data were extracted from full-text versions of studies, where available (i.e., abstracts or posters were not used unless an abstract or poster was the terminal source document). Where mature data from a single trial were reported later, the most recent data were used in the analysis.

\section{Outcome evaluation}

The outcomes studied were OS and PFS, which were evaluated in terms of relative mean survival compared to the reference treatment (docetaxel $75 \mathrm{mg} / \mathrm{m}^{2}$ ). Although clinical trials typically report hazard ratios and median survival times, the fitting of parametric models to survival data lends itself more readily to the estimation of mean survival. Mean survival times are of particular importance to cost-effectiveness analyses, which are part of the health technology assessment process. Mean survival was estimated as the area under the probability of survival curve with a horizon of 60 years. Relative differences were assessed and mean estimates with 95\% credible intervals presented. In addition, significance tests were performed on the difference between two distributions. The minimum of the proportions greater or less than 0 was used as a probability and converted to a two-tailed test by multiplying it by 2 [19]. These values can be interpreted in the same way as $P$ values from a frequentist analysis, although they do not have the same statistical definition. Rank probability charts, cumulative probability charts and surface under the cumulative ranking (SUCRA) were also derived following the methods described by Salanti et al. [20]. However, caution is needed when interpreting SUCRA scores or associated rankings because they can be biased when interventions are not represented equally in a network and/or, interventions are not connected to the same reference treatment $[21,22]$. The efficacy of each intervention was evaluated for each combination of NSCLC factors, namely EGFR mutation positive (versus EGFR mutation negative), squamous versus nonsquamous, and PD-L1 expression $<5 \%$ versus $\mathrm{PD}-\mathrm{L} 1$ expression $\geq 5 \%$ (PD-L1 expression $<1 \%$ vs. PD-L1 expression $\geq 1 \%$ was also studied, but only the full results for the $5 \%$ cut-off are presented), which together defined 16 distinct subgroups. Studies investigating TKI regimens included only TKI-naïve patients, and studies investigating nivolumab included only PD-L1 immunotherapy--naïve patients.

\section{Statistical analysis}

Kaplan-Meier charts were digitized using the DigitizeIt software package [23], and the method described by Guyot et al. [24] was used to reconstruct patient-level data. All of the data were plotted to check for evidence of nonproportional hazards and tests of significance performed using the method described by Grambsch and Therneau [25] based on a Kaplan-Meier transformation. The method presented by Jansen [12] was used to fit first- and second-order fractional polynomial models. In addition, hazard ratios and confidence intervals also were extracted and summarized as log (hazard ratios) and standard errors. The log (hazard ratios) were used to estimate Higgin's $I^{2}$ [26], which provides a measure of the percentage of variance explained by heterogeneity and/or inconsistency. Pairwise meta-analyses of duplicate comparisons and two types of node-splitting (traditional node-splitting [27], which detects only inconsistency for a closed loop in the network of evidence, and an experimental node-splitting [28], which assumes inconsistency is another measure of heterogeneity) also were conducted. The log (hazard ratios) were used to perform NMAs; this followed the method described by Woods et al. [29]. If a study did not provide complete information on hazard ratio estimates, the hazard ratios were estimated using the reconstructed patient-level data where possible; if not available, the hazard ratios were derived from median survival times and sample size following the method described by Hackshaw [30]. All the NMAs were extended using hierarchical exchangeable structures by adapting the code presented by Owen et al. [31]. Hierarchical exchangeable structures allow treatment effects to vary by covariates independently of the other treatments in the network of evidence. The treatment effect remains constant for any treatment not specified within a hierarchical exchangeable structure. The efficacy of EGFR TKIs was allowed to vary by EGFR mutation status (evidence supported by Wang et al. [32]; Lim et al. [33]; Sun et al. [34]; Urata et al. [35]; Vale et al. [17]). Further, pemetrexed was allowed to vary by histology (supported by evidence from Kubota et al. [36]; Scagliotti et al. [37]), nintedanib was allowed to vary by histology (supported by evidence from Reck et al. [38]), and nivolumab was allowed to vary by PD-L1 expression and histology (supported by evidence from Borghaei et al. [39]; Brahmer et al. [40]). Predictions were made for all combinations of these subgroups. In addition, where possible, different doses also were included as a hierarchical structure with an overall treatment class effect. Constraints were imposed to ensure that the efficacy increased with dose intensity (docetaxel $75 \mathrm{mg} / \mathrm{m}^{2}$ every 3 weeks $\rightarrow$ docetaxel $60 \mathrm{mg} / \mathrm{m}^{2}$ every 3 weeks $\rightarrow$ weekly lower-dose docetaxel) and where there was external supporting evidence for the treatment covariate interactions (EGFR TKIs with EGFR mutation status and pemetrexed with histology). Where there was sufficient evidence for 
subpopulation results within a trial, these were used instead of the overall study-level results. Subgroup data were used in the NMA only where we had a reason to suspect there should be a difference between subgroups, or there was supporting evidence in the literature, or a treatment had an indication for a subgroup. Studies that did not present the relevant proportion of patients with a given tumor subtype were not included in the NMA, i.e., pemetrexed and proportion of patients with nonsquamous tumors not reported, TKIs and proportion of patients with tumors that were EGFR mutation positive not reported, and PD-L1 immunotherapies with proportion of patients with PD-L1 expression not reported. The following studylevel covariates were included one at a time to see if they improved model fit: time since publication, proportion of patients with nonsquamous tumors, mean age, proportion of patients with Eastern Cooperative Oncology Group $(E C O G) \geq 1$, proportion of patients with metastatic disease, and proportion of Asian patients.

Noninformative priors were used for treatment efficacy and for between-study variances. For the fractional polynomial model, four random-effects models were conducted: first-order fractional polynomial NMA with an additional heterogeneity parameter for scale, first-order fractional polynomial NMA with additional heterogeneity parameters for scale and shape, second-order fractional polynomial NMA with an additional heterogeneity parameter for scale, and second-order fractional polynomial NMA with additional heterogeneity parameters for scale and the two shape parameters. A range of power functions were fitted for first- and second-order fractional polynomial models, which followed that of Jansen [12].

Posterior sampling was performed using Markov Chain Monte Carlo, with three chains of 70,000 iterations per chain, each with a burn-in of 30,000 iterations for the fractional polynomial models and a total of 120,000 iterations for the hazard ratio models. Convergence was assessed through iteration plots, the shape of the posterior distributions, and Gelman-Rubin diagnostics [41]. Bayesian NMAs were performed using JAGS software [42] within R 3.1.3 [43]. Heterogeneity tests were performed using the netmeta package in R [44] and node-splitting was performed using the geMTC package in R [45]. Further details and the JAGS code are provided in the Additional file 1.

Further analyses were required to estimate mean survival times. For the hazard ratio approach, all of the reconstructed patient-level data for the reference data were collated. Bayesian first-order and second-order fractional polynomial models were fitted to these data with heterogeneity parameters for all scale and shape parameters. The same number of iterations and chains was used as stated for the hazard ratio NMA. A grid search for the best-fitting model with up to two covariates was performed.
The efficacy of study treatments in each tumor subgroup was estimated by linear extrapolation of the parameters available for each proportion of the relevant tumor type. If not all of the required information was available, the efficacy of a combination regimen was estimated using the separate information from monotherapy regimens.

\section{Results}

\section{Search results}

We screened 2601 records and 30 trials evaluating 17 interventions for inclusion in the NMA (Fig. 1 and Table 1). Characteristics of included studies are provided in Table 1. The network diagrams for OS and PFS are shown in Figs. 2 and 3, respectively. A bias assessment of the included studies is presented in Additional file 1: Table S1. The bias assessment showed that a high proportion of studies were open label, with physicians and patients not blinded to treatment. An additional cause of concern was treatment switching in the study by Kawaguchi et al. [46], which was the only study that connected docetaxel $\left(60 \mathrm{mg} / \mathrm{m}^{2}\right)$ to the rest of the network. This study used erlotinib $(150 \mathrm{mg})$ as the comparator in a patient population with 16\% EGFR mutation-positive tumors in the erlotinib arm and $25 \%$ in the docetaxel arm. The treatment switching, therefore, was likely to have caused confounding by potentially increasing the perceived relative efficacy for docetaxel (60 $\mathrm{mg} / \mathrm{m}^{2}$ ), although the use of constraints prevented this reversal from being observed. The data for OS, including hazard ratios, median survival times, and covariate data, are presented in Additional file 1: Table S2. The covariate data from this table shows some differences between studies for the proportion of patients restricted in activity (performance status $(E C O G) \geq 1=0.48-0.94$ ), stage of disease (stage IV $=0.53-1.0$ ), and proportion of Asian patients (0.01-1.0); although none of these covariates appeared to improve the fit of the NMAs.

The study designs and reporting of trials studying PD-L1 immunotherapies also was an issue. Brahmer et al. [40] and Borghaei et al. [39] studied nivolumab versus docetaxel in patient populations without any restriction on PD-L1 expression and presented the results for $<1 \%$ versus $\geq 1 \%$, $<5 \%$ versus $\geq 5 \%$, and $<10 \%$ versus $\geq 10 \%$. However, Herbst et al. [18] included only patients with PD-L1 expression of $\geq 1 \%$ and results were stratified as 1 to $49 \%$ and $\geq 50 \%$. The approach undertaken for the NMA relied on being able to estimate the efficacy of regimens for the full range of patient types; in the absence of information on how pembrolizumab performed in a low PD-L1 expression population, the Herbst study was excluded from the NMA. This left us with the choice for which of the cut-offs presented by Brahmer et al. [40] and Borghaei et al. [39] to present in this study. The results for the 5 and $10 \%$ cut-offs were closer to each other and appeared to be more consistent than the $1 \%$ cut-off results, i.e., efficacy improved for both 


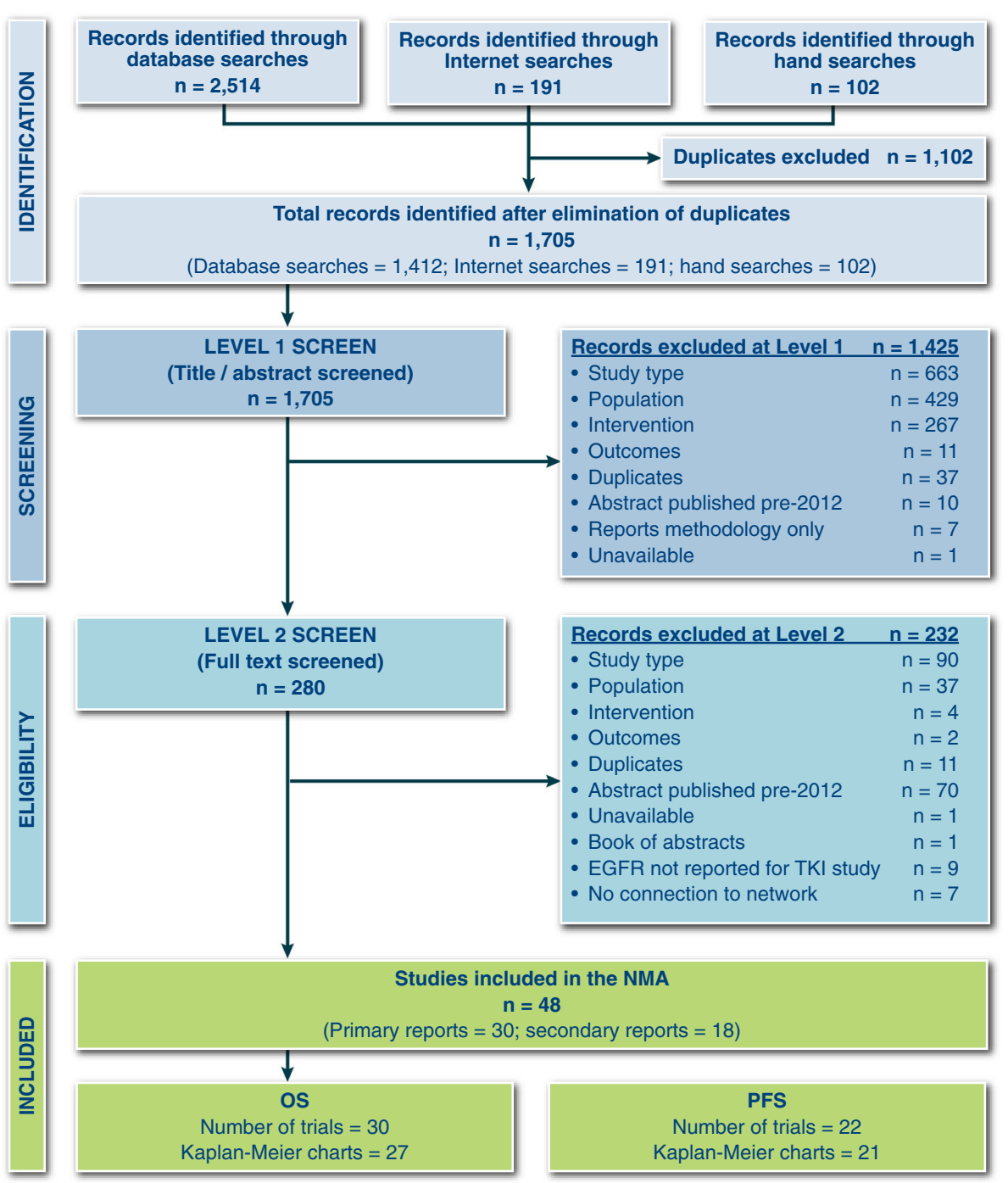

Fig. 1 PRISMA Chart. PRISMA = Preferred Reporting Items for Systematic Reviews and Meta-Analyses. Note: Some studies were reported in multiple publications; in such cases, the main study report was classed as the "primary" publication, and any other articles reporting on the same trial were classed as "secondary reports." Therefore, the primary reports are all unique trials

OS and PFS, with higher PD-L1 expression values for both studies, for the 5 and $10 \%$ cut-offs, whereas the $1 \%$ cut-off results reported by Brahmer et al. [40] appeared to show a reversal in this pattern, although this was not statistically significant. The 5\% cut-off data therefore were selected because they represented the mid cut-off presented and appeared to give more consistent results. The overall results in which nivolumab showed a significant benefit over docetaxel $(150 \mathrm{mg})$ were not affected by the choice between the 1 and 5\% cut-offs for either the fixed-effects or random-effects models for OS and PFS.

\section{Proportional hazards, heterogeneity and inconsistency, and modeling issues}

An assessment of the proportional hazards assumption and heterogeneity and inconsistency is provided in the
Additional file 1. The assessment indicated that the proportional hazards assumption was mainly an issue for PFS (2 out of 32 studies had nonproportional hazards for OS, and 7 out of 29 studies had nonproportional hazards for PFS) and that the exchangeable hierarchical structures were needed for all the NMAs fitted. The main evidence for the difference in efficacy of TKIs in the network of evidence came from the subgroup data presented by Urata et al. [35]. For OS, these data were presented only as median survival times compared to all Kaplan-Meier estimates available for PFS. The fitting of fractional polynomial models for OS was problematic because these models were not able to differentiate between the efficacy of TKIs for EGFR mutation-negative and mutation-positive tumor types. However, the hazard ratio NMAs were able to demonstrate a difference in 
Table 1 Characteristics of included studies in the network of evidence

\begin{tabular}{|c|c|c|c|}
\hline Study & Restriction & Interventions & $\mathrm{N}$ \\
\hline \multirow{2}{*}{$\begin{array}{l}\text { Aerts et al. (2013) [49] } \\
\text { (NVALT-10) }\end{array}$} & \multirow[t]{2}{*}{ Nonsquamous histology } & Erlotinib (150 mg) & 73 \\
\hline & & $\begin{array}{l}\text { Erlotinib }(150 \mathrm{mg})+ \\
\text { pemetrexed }\left(500 \mathrm{mg} / \mathrm{m}^{2}\right)\end{array}$ & 82 \\
\hline \multirow{2}{*}{$\begin{array}{l}\text { Aerts et al. (2013) [49] } \\
\text { (NVALT-10) }\end{array}$} & \multirow[t]{2}{*}{ Squamous histology } & Erlotinib (150 mg) & 42 \\
\hline & & $\begin{array}{l}\text { Docetaxel }\left(75 \mathrm{mg} / \mathrm{m}^{2}\right)+ \\
\text { erlotinib }(150 \mathrm{mg})\end{array}$ & 34 \\
\hline \multirow[t]{2}{*}{ Auliac et al. (2014) [50] } & \multirow[t]{2}{*}{ EGFR mutation negative or unknown } & Docetaxel $(75$ mg/m²) & 74 \\
\hline & & $\begin{array}{l}\text { Docetaxel }\left(75 \mathrm{mg} / \mathrm{m}^{2}\right)+ \\
\text { erlotinib }(150 \mathrm{mg})\end{array}$ & 73 \\
\hline \multirow{2}{*}{$\begin{array}{l}\text { Borghaei et al. (2015) [39] } \\
\text { (CheckMate 057) }\end{array}$} & \multirow[t]{2}{*}{ Not restricted } & Docetaxel $(75$ mg/m²) & 224 \\
\hline & & Nivolumab 3 mg/kg & 231 \\
\hline \multirow{2}{*}{$\begin{array}{l}\text { Brahmer et al. (2015)e [40] } \\
\text { (CheckMate 017) }\end{array}$} & \multirow[t]{2}{*}{ Not restricted } & Docetaxel $(75$ mg/m²) & 108 \\
\hline & & Nivolumab 3 mg/kg & 117 \\
\hline \multirow[t]{2}{*}{ Camps et al. (2006) [51] } & \multirow[t]{2}{*}{ Not restricted } & Docetaxel $(75$ mg/m²) & 129 \\
\hline & & Frequent low-dose docetaxel & 125 \\
\hline \multirow[t]{2}{*}{ Fossella (2000) [52] } & \multirow[t]{2}{*}{ Not restricted } & Docetaxel $(75$ mg/m²) & 125 \\
\hline & & Docetaxel $(100$ mg/m²) & 125 \\
\hline \multirow[t]{2}{*}{ Garassino et al. (2013) [53] (TAlLOR) } & \multirow[t]{2}{*}{ EGFR mutation negative } & Docetaxel $(75$ mg/m²) & 110 \\
\hline & & Erlotinib $150 \mathrm{mg}$ & 109 \\
\hline \multirow[t]{2}{*}{ Garon et al. (2014) [54] (REVEL) } & \multirow[t]{2}{*}{ Not restricted } & Docetaxel $(75$ mg/m²) & 618 \\
\hline & & $\begin{array}{l}\text { Docetaxel }(75 \text { mg/m²) + } \\
\text { ramucirumab }(10 \mathrm{mg} / \mathrm{kg})\end{array}$ & 622 \\
\hline \multirow[t]{2}{*}{ Gervais et al. (2005) [55] } & \multirow[t]{2}{*}{ Not restricted } & Docetaxel $(75$ mg/m²) & 62 \\
\hline & & Frequent low-dose docetaxel & 63 \\
\hline \multirow{2}{*}{$\begin{array}{l}\text { Gridelli et al. (2004) [56] } \\
\text { (DISTAL 01) }\end{array}$} & \multirow[t]{2}{*}{ Not restricted } & Docetaxel $\left(75 \mathrm{mg} / \mathrm{m}^{2}\right)$ & 110 \\
\hline & & Frequent low-dose docetaxel & 110 \\
\hline \multirow[t]{2}{*}{ Han et al. (2011) [57] } & \multirow[t]{2}{*}{ Not restricted } & Docetaxel $(75$ mg/m²) & 40 \\
\hline & & Pemetrexed $(500$ mg/m²) & 44 \\
\hline \multirow{2}{*}{$\begin{array}{l}\text { Hanna et al. (2004) [58]; } \\
\text { Scagliotti et al. (2009) [37] }\end{array}$} & \multirow[t]{2}{*}{ Not restricted } & Docetaxel $(75$ mg/m²) & 288 \\
\hline & & Pemetrexed $(500$ mg/m²) & 283 \\
\hline \multirow{2}{*}{$\begin{array}{l}\text { Hanna et al. (2013) [59] } \\
\text { (LUME-Lung 2) }\end{array}$} & Not restricted & Pemetrexed $(500$ mg/m²) & 360 \\
\hline & & $\begin{array}{l}\text { Pemetrexed }\left(500 \mathrm{mg} / \mathrm{m}^{2}\right)+ \\
\text { nintedanib }(200 \mathrm{mg})\end{array}$ & 353 \\
\hline Hosomi et al. (2015) [60] & Asian population & Docetaxel $(60$ mg/m²) & 81 \\
\hline & & $\begin{array}{l}\text { Docetaxel }(60 \text { mg/m² })+ \\
\text { ramucirumab }(10 \mathrm{mg} / \mathrm{kg})\end{array}$ & 76 \\
\hline Juan et al. (2015) [61] & Not restricted & Erlotinib (150 mg) & 35 \\
\hline & & $\begin{array}{l}\text { Docetaxel }\left(75 \mathrm{mg} / \mathrm{m}^{2}\right)+ \\
\text { erlotinib }(150 \mathrm{mg})\end{array}$ & 33 \\
\hline Karampeazis et al. (2013) & Not restricted & Erlotinib (150 mg) & 39 \\
\hline & & Pemetrexed $(500$ mg/m²) & 36 \\
\hline Katakami et al. (2014) [63] / & Asian population & Erlotinib (150 mg) & 252 \\
\hline & & Gefitinib (250 mg) & 250 \\
\hline Kawaguchi et al. (2014) & Asian population & Erlotinib (150 mg) & 150 \\
\hline [46] (DELIA) & & Docetaxel $(60$ mg/m²) & 151 \\
\hline Kim et al. (2008) [64] & Not restricted & Docetaxel $(75$ mg/m²) & 710 \\
\hline & & Gefitinib (250 mg) & 723 \\
\hline
\end{tabular}


Table 1 Characteristics of included studies in the network of evidence (Continued)

\begin{tabular}{|c|c|c|c|}
\hline Study & Restriction & Interventions & $\mathrm{N}$ \\
\hline \multirow[t]{2}{*}{ Kim et al. (2014) [65] } & \multirow[t]{2}{*}{ Asian population } & Pemetrexed $\left(500 \mathrm{mg} / \mathrm{m}^{2}\right)$ & 45 \\
\hline & & Gefitinib (250 mg) & 43 \\
\hline \multirow[t]{3}{*}{ Lee et al. (2013) [66] } & \multirow[t]{3}{*}{ Not restricted } & Erlotinib (150 mg) & 82 \\
\hline & & Pemetrexed $\left(500 \mathrm{mg} / \mathrm{m}^{2}\right)$ & 77 \\
\hline & & $\begin{array}{l}\text { Erlotinib }(150 \mathrm{mg})+ \\
\text { pemetrexed }\left(500 \mathrm{mg} / \mathrm{m}^{2}\right)\end{array}$ & 75 \\
\hline \multirow[t]{2}{*}{ Nishino et al. (2015) [67] } & \multirow[t]{2}{*}{$\begin{array}{l}\text { Nonsquamous histology } \\
\text { Asian population }\end{array}$} & $\begin{array}{l}\text { Docetaxel }\left(60 \mathrm{mg} / \mathrm{m}^{2}\right)+ \\
\text { bevacizumab }(15 \mathrm{mg} / \mathrm{kg})\end{array}$ & 45 \\
\hline & & $\mathrm{S}-1\left(40 \mathrm{mg} / \mathrm{m}^{2}\right)+$ bevacizumab $(15 \mathrm{mg} / \mathrm{kg})$ & 45 \\
\hline \multirow[t]{2}{*}{ Quoix et al. (2004) [68] } & \multirow[t]{2}{*}{ Not restricted } & Docetaxel $(75$ mg/m²) & 93 \\
\hline & & Docetaxel $\left(100 \mathrm{mg} / \mathrm{m}^{2}\right)$ & 89 \\
\hline \multirow{2}{*}{$\begin{array}{l}\text { Reck et al. (2014) [38] } \\
\text { (LUME-Lung 1) }\end{array}$} & \multirow[t]{2}{*}{ Not restricted } & Docetaxel $(75$ mg/m²) & 615 \\
\hline & & $\begin{array}{l}\text { Docetaxel }\left(75 \mathrm{mg} / \mathrm{m}^{2}\right)+ \\
\text { nintedanib }(200 \mathrm{mg})\end{array}$ & 598 \\
\hline \multirow[t]{2}{*}{ Schuette et al. (2005) [69] } & \multirow[t]{2}{*}{ Not restricted } & Docetaxel $(75$ mg/m²) & 103 \\
\hline & & Frequent low-dose docetaxel & 105 \\
\hline \multirow[t]{2}{*}{ Shepherd et al. (2000) [70] } & \multirow[t]{2}{*}{ Not restricted } & Docetaxel $(75$ mg/m²) & 55 \\
\hline & & Best supportive care & 49 \\
\hline \multirow{2}{*}{$\begin{array}{l}\text { Sun et al. (2012) [34] } \\
\text { (KCSG-LU08-01) }\end{array}$} & \multirow{2}{*}{$\begin{array}{l}\text { Adenocarcinoma histology } \\
\text { Asian population }\end{array}$} & Pemetrexed $(500$ mg/m²) & 67 \\
\hline & & Gefitinib (250 mg) & 68 \\
\hline \multirow{2}{*}{$\begin{array}{l}\text { Sun et al. (2013) [71] } \\
\text { (JMID) }\end{array}$} & \multirow[t]{2}{*}{ Asian population } & Docetaxel $(75$ mg/m²) & 98 \\
\hline & & Pemetrexed $\left(500 \mathrm{mg} / \mathrm{m}^{2}\right)$ & 104 \\
\hline \multirow{2}{*}{$\begin{array}{l}\text { Takeda et al. (2015;2016) } \\
{[72,73]}\end{array}$} & \multirow{2}{*}{$\begin{array}{l}\text { Nonsquamous histology } \\
\text { Progressed after treatment } \\
\text { with bevacizumab plus a } \\
\text { platinum-based doublet. } \\
\text { Asian population }\end{array}$} & Docetaxel $(60$ mg/m²) & 50 \\
\hline & & $\begin{array}{l}\text { Docetaxel }\left(60 \mathrm{mg} / \mathrm{m}^{2}\right)+ \\
\text { bevacizumab }(15 \mathrm{mg} / \mathrm{kg})\end{array}$ & 50 \\
\hline \multirow{2}{*}{$\begin{array}{l}\text { Zhou et al. (2013;2014) } \\
{[74,75]}\end{array}$} & \multirow{2}{*}{$\begin{array}{l}\text { Nonsquamous histology } \\
\text { EGFR mutation negative } \\
\text { Asian population }\end{array}$} & Pemetrexed $\left(500 \mathrm{mg} / \mathrm{m}^{2}\right)$ & 76 \\
\hline & & Gefitinib (250 mg) & 81 \\
\hline
\end{tabular}

efficacy of TKIs by EGFR status; and because the evidence for nonproportional hazards for OS was weak, the results presented for OS are those based on the hazard ratio NMA. The hazard ratios for OS were applied to fractional polynomial model fitted to the reference treatment (docetaxel $75 \mathrm{mg} / \mathrm{m}^{2}$ ) from the network of evidence. Details of this model are given in the Additional file 1 and predicted survival curves by tumor histology presented in Additional file 1: Figure S1. The fractional polynomial model for PFS did not have these issues, and so this was the model used to present PFS results. For both these NMAs, the random-effects models did not improve model fit over the fixed-effects results; only the fixed-effects results are presented in the main body of the text; random-effects results are presented in Additional file 1: Tables S3 and S4 for OS and PFS, respectively, for more details.

The fitting of fractional polynomial models to multiple treatment data can result in survival curves that flatten before reaching zero, especially for second-order models with time-varying treatment effects. (All predictions by treatment are shown in Additional file 1: Figure S2.) This was observed in the NMAs fitted using this technique. The hazard rates therefore were estimated up to the end of follow-up for the available evidence by intervention; after this point had been reached, the hazard rates from the reference treatment were used.

\section{Presentation of results}

The results for the eight subgroups are presented in the following subsections and in the Additional file 1. Only main figures for the subgroup representing the largest population (nonsquamous, EGFR mutation negative, and PD-L1 expression $<5 \%$ ) are presented in the manuscript. The full set of results for each subgroup can be in found in the Additional file 1: Figures S3-S48). The Additional file 1 provides survival probability curves, mean survival times, and relative differences in mean survival 


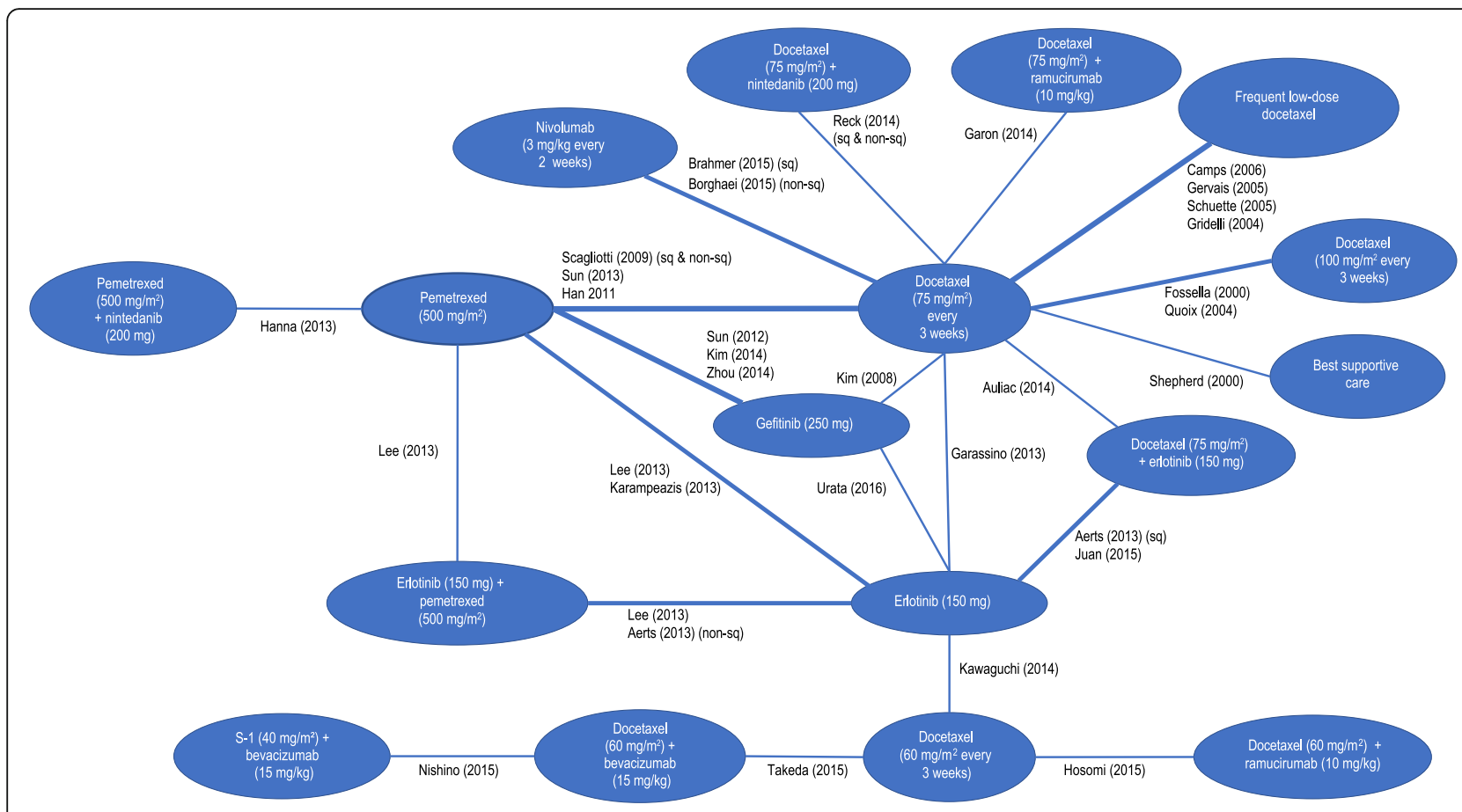

Fig. 2 Network of Evidence for Overall Survival

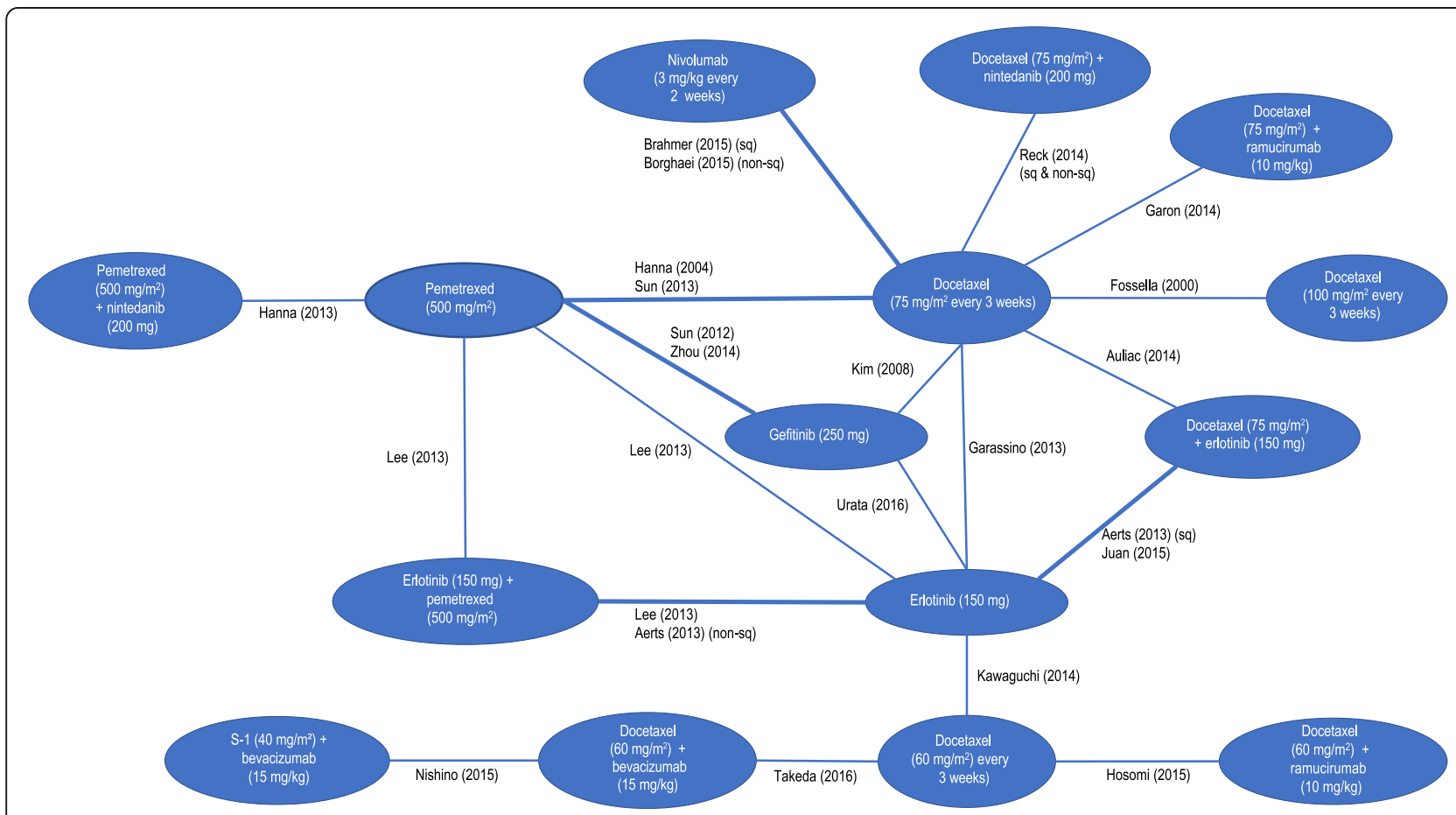

Fig. 3 Network of Evidence for Progression-Free Survival 
for OS and PFS, by subgroup. A summary table for all the results by subgroups is provided in Table 2. SUCRA scores are not presented due to apparent bias with this network of evidence and because they were found to not be consistent with relative differences and credible intervals. This was particularly the case for treatments represented by a small sample size and located on the periphery of the network of evidence.

\section{Results by subgroup}

\section{Nonsquamous, PD-L1 expression $<5 \%$ and EGFR negative}

For OS, docetaxel plus ramucirumab and docetaxel plus nintedanib were the only interventions that showed a significant improvement in mean survival time over docetaxel $\left(75 \mathrm{mg} / \mathrm{m}^{2}\right)$ with gains of 2.3 and 2.6 months, respectively (Fig. 4). Survival curves and mean OS times are shown in Additional file 1: Figure S3. For PFS, only docetaxel plus ramucirumab gave a significant benefit, of 1.2 months, in mean survival (Fig. 5). Mean PFS survival times are presented in Additional file 1: Figure S6.

\section{Squamous, PD-L1 expression $<5 \%$ and EGFR negative}

For OS, docetaxel plus ramucirumab and nivolumab were the only interventions that showed a significant improvement in mean survival over docetaxel $\left(75 \mathrm{mg} / \mathrm{m}^{2}\right)$ with a gain of 2.0 and 5.5 months, respectively (Additional file 1: Figures S7-S9). For PFS, only docetaxel plus ramucirumab gave a significant benefit, of 1.2 months, in mean survival, and nivolumab showed borderline significance $(P=0.0508)$ with 2.6 months (Additional file 1: Figures S10-S12).

\section{Nonsquamous, PD-L1 expression $\geq 5 \%$ and EGFR negative}

For OS, nivolumab, docetaxel plus ramucirumab and docetaxel plus nintedanib showed a significant improvement in mean survival over docetaxel $\left(75 \mathrm{mg} / \mathrm{m}^{2}\right)$ with gains of $12.9,2.3$, and 2.6 months, respectively (Additional file 1: Figures S13-S15). For PFS, only nivolumab and docetaxel plus ramucirumab gave a significant benefit of 5.0 and 1.2 months, respectively (Additional file 1: Figures S16-S18). Nivolumab showed significant superiority over docetaxel plus ramucirumab and docetaxel plus nintedanib $(P<0.05)$ for OS and PFS.

\section{Squamous, PD-L1 expression $\geq 5 \%$ and EGFR negative}

For OS, nivolumab and docetaxel plus ramucirumab were the only interventions to show a significant improvement in mean survival over docetaxel $\left(75 \mathrm{mg} / \mathrm{m}^{2}\right)$, with a gain of 8.0 and 2.0 months, respectively (Additional file 1: Figures S19-S21). For PFS, nivolumab and docetaxel plus ramucirumab also showed statistically significant benefits of 5.7 and 1.2 months, respectively (Additional file 1: Figures S22-S24). Nivolumab showed significant superiority over docetaxel plus ramucirumab $(P<0.05)$ for PFS.

\section{Nonsquamous, PD-L1 expression < 5\% and EGFR positive}

For OS, the following treatments showed a significant gain over docetaxel $\left(75 \mathrm{mg} / \mathrm{m}^{2}\right)$ (difference in months for mean survival shown in parentheses): docetaxel plus erlotinib (13.4), erlotinib plus pemetrexed (8.0), erlotinib (7.4), gefitinib (4.4), docetaxel plus nintedanib (2.6), and docetaxel plus ramucirumab (2.3) (Additional file 1: Figures S25-S27). For PFS, the following treatments showed a significant gain over docetaxel $\left(75 \mathrm{mg} / \mathrm{m}^{2}\right)$ (difference in months for mean survival shown in parentheses): docetaxel plus erlotinib (8.1), erlotinib plus pemetrexed (7.0), erlotinib (6.8), gefitinib (5.4), and docetaxel plus ramucirumab (1.2) (Additional file 1: Figures S28-S30). Docetaxel plus erlotinib showed significant superiority $(P<0.05)$ over gefitinib and non-TKI regimens for OS. Docetaxel plus erlotinib, erlotinib, and gefitinib showed significant superiority $(P<0.05)$ over docetaxel plus ramucirumab for PFS.

\section{Squamous, PD-L1 expression $<5 \%$ and EGFR positive}

For OS, the following treatments showed a significant gain over docetaxel $\left(75 \mathrm{mg} / \mathrm{m}^{2}\right.$ ) (difference in months for mean survival shown in parentheses): docetaxel plus erlotinib (11.9), erlotinib (6.5), nivolumab (5.5), gefitinib (3.9), and docetaxel plus ramucirumab (2.0) (Additional file 1: Figures S31-S33). For PFS, the following treatments showed a significant gain over docetaxel $(75$ $\mathrm{mg} / \mathrm{m}^{2}$ ) (difference in months for mean survival shown in parentheses): docetaxel plus erlotinib (8.1), erlotinib (6.8), gefitinib (5.4), and docetaxel plus ramucirumab (1.2) (Additional file 1: Figures S34-S36). Nivolumab showed borderline significance with an increase of 2.6 months. Docetaxel plus erlotinib showed significant superiority $(P<0.05)$ over gefitinib and docetaxel plus ramucirumab for OS. Docetaxel plus erlotinib showed significant superiority $(P<0.05)$ over non-TKI regimens for PFS.

\section{Nonsquamous, PD-L1 expression $\geq 5 \%$ and EGFR positive}

For OS, the following treatments showed a significant gain over docetaxel $\left(75 \mathrm{mg} / \mathrm{m}^{2}\right)$ (difference in months for mean survival shown in parentheses): docetaxel plus erlotinib (13.4), nivolumab (12.9), erlotinib plus pemetrexed (8.0), erlotinib (7.4), gefitinib (4.4), docetaxel plus nintedanib (2.6), and docetaxel plus ramucirumab (2.3) (Additional file 1: Figures S37-S39). For PFS, the following treatments showed significant gains over docetaxel $\left(75 \mathrm{mg} / \mathrm{m}^{2}\right)$ (difference in months for mean survival shown in parentheses): docetaxel plus erlotinib (8.1), erlotinib plus pemetrexed (7.0), erlotinib (6.8), gefitinib (5.4), nivolumab (5.0), and docetaxel plus ramucirumab 


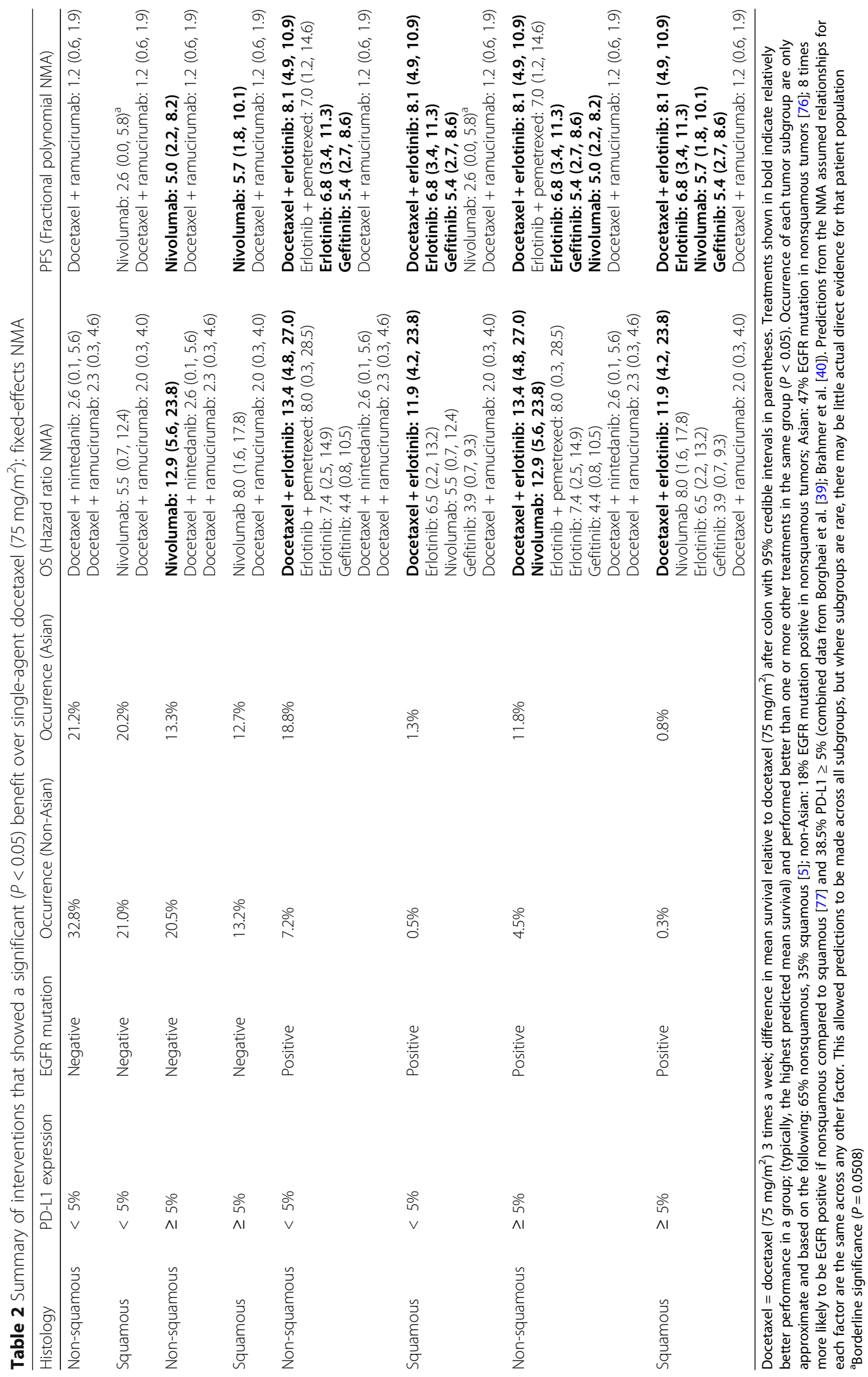




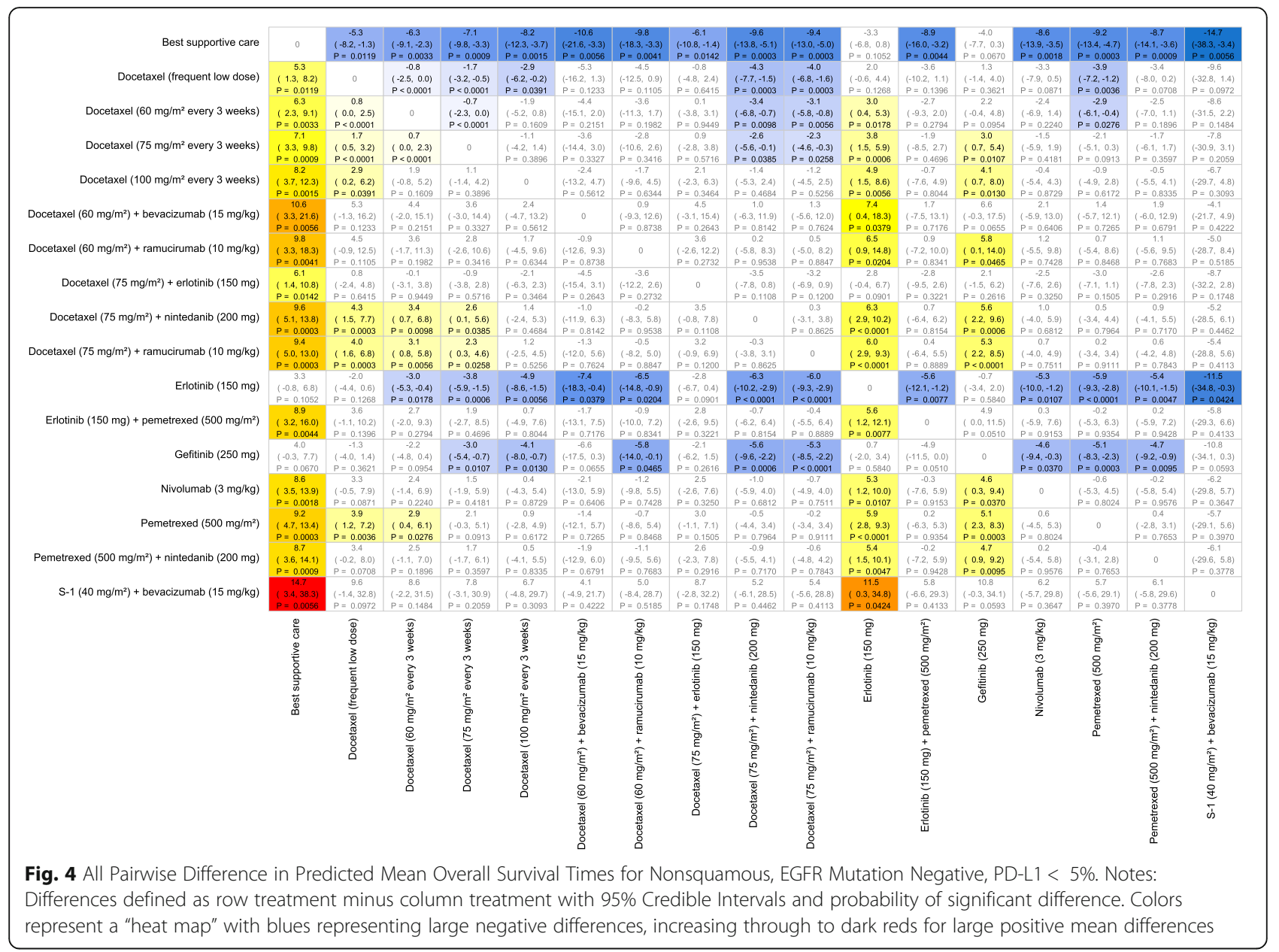

(1.2) (Additional file 1: Figures S40-S42). Docetaxel plus erlotinib and nivolumab showed significant superiority $(P<0.05)$ over docetaxel plus ramucirumab for OS. Docetaxel plus erlotinib, erlotinib, gefitinib, and nivolumab showed significant superiority $(P<0.05)$ over docetaxel plus ramucirumab for PFS.

\section{Squamous, $P D-L 1$ expression $\geq 5 \%$ and EGFR positive}

For OS, the following treatments showed significant gains over docetaxel $\left(75 \mathrm{mg} / \mathrm{m}^{2}\right)$ (difference in months for mean survival shown in parentheses): docetaxel plus erlotinib (11.9), nivolumab (8.0), erlotinib (6.5), gefitinib (3.9), and docetaxel plus ramucirumab (2.0) (Additional file 1: Figures S43-S45). For PFS, the following treatments showed significant gains over docetaxel $\left(75 \mathrm{mg} / \mathrm{m}^{2}\right)$ (difference in months shown in parentheses): docetaxel plus erlotinib (8.1), erlotinib (6.8), nivolumab (5.7), gefitinib (5.4), and docetaxel plus ramucirumab (1.2) (Additional file 1: Figures S46-S48). Docetaxel plus erlotinib showed significant superiority $(P<0.05)$ over docetaxel plus ramucirumab for OS. Docetaxel plus erlotinib, erlotinib, nivolumab, and gefitinib showed significant superiority $(P<0.05)$ over
non-TKI regimens and non-PD-1 immunotherapies for PFS.

\section{Summary of results by subgroup}

Table 2 summarizes all the interventions that showed a significant gain over docetaxel $\left(75 \mathrm{mg} / \mathrm{m}^{2}\right)$ by subgroup, including the difference in mean survival. Sensitivity analyses for random-effects models also were performed, and these are presented in Additional file 1: Table S5. These tables show how the optimal treatments change with each subgroup. TKI based regimens consistently showed the greatest benefit over docetaxel $\left(75 \mathrm{mg} / \mathrm{m}^{2}\right)$ in patients with EGFR mutation positive tumor types regardless of histology. However, in the PD-L1 high expression group nivolumab showed a similar benefit to the TKI based regimens in patients with EGFR mutation positive tumor types. For the nonsquamous, low PD-L1 expression EGFR mutation negative subgroups, ramucirumab plus docetaxel and nintedanib plus docetaxel provided the greatest benefit. Combination treatments such as docetaxel plus erlotinib appeared to give the greatest benefit in certain subgroups but there was a greater 


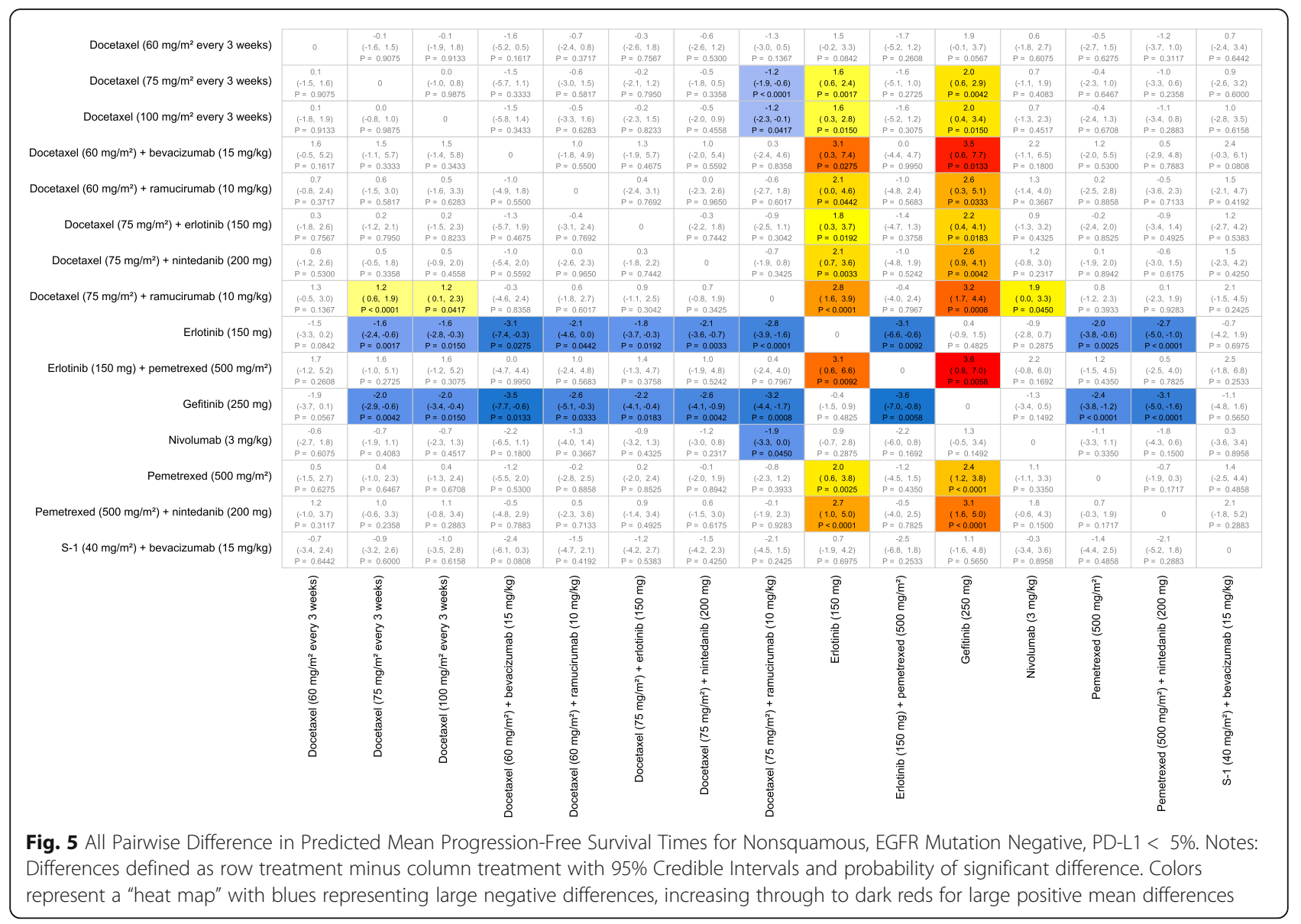

uncertainty in these predictions which was reflected in the large credible intervals.

\section{Discussion}

The results from this study provide further evidence that it is important to appropriately target specific treatments for particular patient groups to optimize outcomes. The mean survival times reported in this study also were in agreement with previous NMAs. The improvement in OS, using the hazard ratio model applied to a fractional polynomial model for the reference treatment in this study, matched closely those reported by Jansen [12] for a second-order fractional polynomial model fitted to reconstructed data for results where patient groups were not a factor (docetaxel vs. best supportive care: Jansen [12], 6.8 months; this study, 7.1 months for nonsquamous and 6.3 months for squamous); mean OS for docetaxel: Jansen [12], 13.0 months; this study, nonsquamous, 14.2 months and squamous, 12.7 months). The fractional polynomial models fitted to OS, which were not presented, also showed comparable mean survival times with those from the hazard ratio model, with the exception of the TKIs.

The main strengths of this study were that data were identified by a systematic literature review and that model flexibility allowed particular treatments to vary by histology, PD-L1 expression, and EGFR mutation. In addition, the survival curves for the reference treatment were validated using the data from Penrod et al. [47]. Heterogeneity and inconsistency were thoroughly investigated using pairwise meta-analyses of duplicate comparisons and node-splitting. The inclusion of hierarchical exchangeable structures in the models appeared to have sufficiently explained the heterogeneity and inconsistency observed to the point where fixed-effects models produced better goodness of fit statistics than random-effects models. This is the first study we know of that models the efficacy of interventions for NSCLC by histology, PD-L1 expression, and EGFR mutation status within an NMA. Some of these interactions have been only recently discovered, and it is likely that our understanding will continue to increase as more research is conducted.

The main study limitation was the variable length of follow-up time between studies, which meant there was some uncertainty in the extrapolation of OS and PFS survival curves. For OS, the hazard ratios models were simply applied to the reference model by histology, so treatment effects were assumed to continue after follow-up. However, 
to ensure PFS survival curves were plausible, the hazard rates from the reference treatment were used once the time exceeded the maximum follow-up data for a given intervention. Interventions with shorter follow-up times but that appeared to have lower hazard rates than the reference treatments therefore may have been at a disadvantage. However, the approach used in this study did make full use of the available data. The proportion of patients tested for EGFR mutation status varied across studies and may have been a source of bias. EGFR mutation also covers different genetic markers and other factors, such as EGFR copy number, although these may not be independent predictive markers [32]. The predictions for combination treatments were partly based on extrapolation from singleinterventions results, so there is additional uncertainty around these estimates. This uncertainty mainly concerns docetaxel plus erlotinib because the studies that included this regimen contained low proportions of EGFR mutation-positive patients. The increased survival benefit predicted for patients receiving docetaxel plus erlotinib who have tumors that are EGFR mutation positive was based on the associated efficacy of erlotinib monotherapy with EGFR mutation status. Assumptions were also needed to make predictions for each of the tumor subtypes. Some studies reported results for nonsquamous tumors and squamous whilst other studies were restricted to adenocarcinoma. For this study, we assumed that nonsquamous and adenocarcinoma were equivalent to each other. Some of the tumor subtypes are rare such as squamous tumors that are EGFR mutation positive, and because only study level covariate data were reported we do not know whether all patient types existed in the data analyzed. The association of a change in efficacy for a particular treatment with a tumor characteristic was assumed to hold across all tumor types. Some caution may therefore be needed in interpreting the predictions for the rarer subgroups or where a tumor characteristic such as PD-L1 expression was only reported in a small number of studies because, for this example, only comparative data for nivolumab were presented by PD-L1 expression.

There were inconsistencies between the results for OS and PFS for nintedanib, nivolumab, and S-1 plus bevacizumab, which makes it difficult to be certain of the relative effectiveness of these interventions. The efficacy of docetaxel plus nintedanib and nivolumab were allowed to vary by histology in this study, although the actual trial results for these interventions had not shown there was a significant association with histology (e.g., for nintedanib plus docetaxel: OS, $P=0.1194$; PFS, $P=0.4700$, as stated by Reck et al. [38]). If the efficacy of these regimens had not been allowed to vary by histology, then the efficacy found for nintedanib would have been poorer than the results presented from this study for the nonsquamous subgroup for OS, and also we may not have seen a significant result for nivolumab in the squamous PD-L1 expression population. The evidence for S-1 and bevacizumab was weak in the network studied. This was partly due to small sample sizes and also due to the distance between these treatments and the reference treatment in the network of evidence. It is therefore difficult to draw conclusions for these treatments, especially considering that the results for OS and PFS gave conflicting results. It is also worth noting that some treatments gave a significant change in median survival when the mean survival was not significant, which can be found by viewing the survival curves and looking at the credible intervals at $50 \%$ survival. This was the case for docetaxel plus nintedanib for PFS of both nonsquamous and squamous tumor subtypes, for docetaxel plus nintedanib for the random-effects NMA for PFS of the nonsquamous tumor subtype, and for docetaxel plus ramucirumab for the random-effects NMA for PFS. The focus of mean survival times in this study is therefore considered to be more conservative than if the focus had been on median survival times.

A further more general limitation with NMAs conducted in NSCLC is the rapidly changing landscape of possible therapies. For example, the results from studies of two more PD-1 immunotherapies have been published since the completion of the literature review conducted for our study. Herbst et al. [18] presented the results for pembrolizumab versus docetaxel, and Fehrenbacher et al. [48] presented the results for atezolizumab versus docetaxel. Where comparable data exists for these two studies and for the nivolumab study, they are presented in Additional file 1: Table S6. A more thorough comparison of these treatments has been presented by the Institute for Clinical and Economic Review [14]. The evidence suggested that nivolumab $(3 \mathrm{mg} / \mathrm{kg})$, pembrolizumab $(10 \mathrm{mg} / \mathrm{kg})$, and atezolizumab $(1200 \mathrm{mg})$ show similar efficacy. The evidence for whether nivolumab is effective in patients with squamous NSCLC who have PD-L1 expression of $<1 \%$ or $<5 \%$ appears to be inconclusive. Also, it should be noted that some of the included treatments or combinations may not be approved in specific markets or for specific subpopulations of interest in this study and that some treatments may not be used or recommended to be used in real-world clinical practice. Another limitation is that this study does not address the relative improvements in quality of life compared to survival time or toxicity.

\section{Conclusions}

In conclusion, the overall trends across OS and PFS indicated that there was always at least one intervention that performed better than single-agent docetaxel. Docetaxel plus ramucirumab gave a consistent significant benefit across all NSCLC subtypes. Docetaxel plus nintedanib 
showed a similar efficacy to docetaxel plus ramucirumab in the nonsquamous population. Superiority was observed for regimens containing erlotinib or gefitinib compared to non-TKI regimens when used in patients whose tumors have EGFR mutations, which was expected given the evidence in the literature [17, 32-35]. For patients whose tumors had a PD-L1 expression of $\geq 5 \%$, superiority was observed in those patients who received nivolumab compared to non-PD-L1 immunotherapies. This was particularly evident for patients with nonsquamous NSCLC and PD-L1 expression $\geq 5 \%$. It was not clear whether this was generally the case for patients whose tumor had high PD-L1 expression or whether nivolumab was effective across squamous tumor types, regardless of PD-L1 expression. There was insufficient evidence available to assess bevacizumab and S-1.

New treatments for NSCLC are being developed and studied; these treatments often are specific to particular biomarkers. This will add further complexity to NMAs conducted in this disease area. However, the results from this study should help inform the decision-making process for prescribing currently available treatments and could be used to help power future trials. Results also may be used to serve as a reference for the efficacy of existing treatments for patients with a particular tumor type, where only mixed population evidence so far exists. As far as we know, this is the only NMA in which investigators have attempted to model the treatment covariate interactions present in NSCLC for second-line treatment after disease progression has occurred.

\section{Additional file}

Additional file 1: Risk of bias assessment, study characteristics, sensitivity analyses, subgroup results and Bayesian code. (DOCX 3820 kb)

\section{Abbreviations}

ECOG: Eastern Cooperative Oncology Group; EGFR: Epidermal growth factor receptor; NMA: Network meta-analysis; NSCLC: Non-small cell lung cancer; OS: Overall survival; PD-L1: Programmed-death ligand-1; PFS: Progression-free survival; PRISMA: Preferred Reporting Items for Systematic Reviews and MetaAnalyses; RCT: Randomized clinical trials; SUCRA: Surface under the cumulative ranking; TKl: Tyrosine kinase inhibitors

\section{Acknowledgments}

The authors wish to thank Prof Keith Abrams, Department of Health Sciences, Leicester University for advice during the analysis stage of this manuscript, and two reviewers, Lauren A Byers, MD, and Wei-Xiang Qi, MSc, whose comments led to an improved manuscript.

\section{Funding}

This study was funded by Eli Lilly and Company. Eli Lilly and Company contributed to the design of the study and collection, analysis, and interpretation of data and in writing the manuscript.

\section{Availability of data and materials}

All data used in this manuscript were obtained from the public domain. The data for the NMA for OS are presented in Additional file 1: Table S2. Data for PFS were based on re-created patient level data, from digitized Kaplan-Meier charts, which are summarized in Additional file 1: Figure S2.

\section{Authors' contributions}

KBW, GCC, UK, and M-HJ designed the review. DS, UK, M-HJ provided statistical guidance for the network meta-analysis. JAK provided guidance on clinical aspects of the analysis. JAK and DPC provided guidance on clinical interpretation. ADV conducted the analysis and wrote the manuscript with comments on drafts from KBW, GCC, DS, UK, M-HJ, JAK and DPC. All authors read and approved the final manuscript.

\section{Ethics approval and consent to participate}

Not applicable.

\section{Consent for publication}

Not applicable.

\section{Competing interests}

ADV, DS and JAK are full-time employees of RTI Health Solutions, which received funding from Eli Lilly and Company to conduct this study. As salaried employees, they receive no payment or honoraria directly from Eli Lilly and Company for services rendered. The contract between RTI Health Solutions and the sponsor includes independent publication rights. RTI Health Solutions conducts work for government and private organizations, including pharmaceutical companies. KBW, GCC, UK and M-HJ are employees of Eli Lilly and Company. DPC did not receive any funding from Eli Lilly and Company related to this study.

\section{Publisher's Note}

Springer Nature remains neutral with regard to jurisdictional claims in published maps and institutional affiliations.

\section{Author details}

${ }^{1}$ RTI Health Solutions, The Pavilion, Towers Business Park, Wilmslow Road, Didsbury, Manchester M20 2LS, UK. ²Eli Lilly and Company Limited, Indianapolis, IN, USA. ${ }^{3}$ Eli Lilly and Company Limited, Helsinki, Finland. ${ }^{4}$ Eli Lilly and Company Limited, Windlesham, Surrey, UK. ${ }^{5}$ RTI Health Solutions, Research Triangle Park, NC, USA. ${ }^{6}$ RTI Health Solutions, Waltham, MA, USA.

${ }^{7}$ Ohio State University Medical Center, Columbus, OH, USA.

Received: 20 December 2017 Accepted: 2 April 2019

Published online: 15 April 2019

\section{References}

1. GLOBOCAN. Cancer fact sheet. Lung cancer incidence, mortality and prevalence worldwide in 2012, summary. International Agency for Research on Cancer. 2012. http://globocan.iarc.fr/Pages/fact_sheets_population.aspx. Accessed 7 Mar 2014.

2. Malvezzi M, Bertuccio P, Levi F, La Vecchia C, Negri E. European cancer mortality predictions for the year 2013. Ann Oncol. 2013;24(3):792-800.

3. American Cancer Society. Cancer facts and figures 2017. https://www. cancer.org/content/dam/cancer-org/research/cancer-facts-and-statistics/ annual-cancer-facts-and-figures/2017/cancer-facts-and-figures-2017.pdf. Accessed 18 Oct 2017

4. American Cancer Socity. Lung Cancer. 2019. https://www.cancer.org/cancer/ lung-cancer.html. Accessed 9 Apr 2019.

5. Riess J. Shifting paradigms in non-small cell lung cancer: an evolving therapeutic landscape. Am J Manag Care. 2013;19(19 Suppl):s390-7.

6. Spiro SG, Silvestri GA. The treatment of advanced non-small cell lung cancer. Curr Opin Pulm Med. 2005;11(4):287-91.

7. Reif MS, Rivera MP. Evidence-based outcomes for patients with advanced non-small cell lung cancer. Semin Respir Crit Care Med. 2000;21(5):443-9.

8. Reck M, Heigener DF, Mok T, Soria J-C, Rabe KF. Management of non-smallcell lung cancer: recent developments. Lancet. 2013;382(9893):709-19.

9. Zer A, Leighl NB. Second-line therapy in non-small-cell lung cancer: the DELTA between different genotypes widens. J Clin Oncol. 2014;32(18):1874-81.

10. National Comprehensive Cancer Network. Clinical practice guidelines in oncology: non-small cell lung cancer, version 1. 2016. Available from: http:// www.ncen.org. Accessed 16 Mar 2017.

11. Novello S, Barlesi F, Califano R, Cufer T, Ekman S, Giaj Levra M, et al. Metastatic non-small-cell lung cancer (NSCLC): ESMO Clinical Practice Guidelines for diagnosis, treatment and follow-up. Ann Oncol. 2016; 27(Suppl 5):v1-vi27. 
12. Jansen JP. Network meta-analysis of survival data with fractional polynomials. BMC Med Res Methodol. 2011;11:61.

13. Popat S, Mellemgaard A, Fahrbach K, Martin A, Rizzo M. Kaiser et al. Nintedanib plus docetaxel as second-line therapy in patients with nonsmall-cell lung cancer: a network meta-analysis. Future Oncol. 2015; 11(3):409-20.

14. Institute for Clinical and Economic Review. Treatment options for advanced non-small cell lung cancer: effectiveness, value and value-based price benchmarks. 2016. https://icer-review.org/wp-content/uploads/2016/08/ MWCEPAC_NSCLC_Evidence_Report_Plus_Supplement_101716.pdf. Accessed 5 Jan 2017.

15. Liang W, Wu X, Fang W, Zhao $Y$, Zhihuang $H$, Xue C, et al. Network metaanalysis of erlotinib, gefitinib, afatinib and icotinib in patients with advanced non-small-cell lung cancer harboring EGFR mutations. PLoS One. 2014;9(2): e85245

16. Tan PS, Lopes G, Acharyya S, Bilger M, Haaland B. Bayesian network metacomparison of maintenance treatments for stage IIIb/IV non-small-cell lung cancer (NSCLC) patients with good performance status not progressing after first-line induction chemotherapy: results by performance status, EGFR mutation, histology and response to previous induction. Eur J Cancer. 2015; 51:2330-44.

17. Vale C, Burdett S, Fisher DJ, Navani N, Parmar MKB, Copas AJ, et al. Should tyrosine kinase inhibitors be considered for advanced non-small-cell lung cancer patients with wild type EGFR? Two systematic reviews and metaanalyses of randomized trials. Clin Lung Cancer. 2015;16(3):173-82.

18. Herbst RS, Baas P, Kim D-W, Felip E, Perez-Gracia JL, Han J-Y, et al. Pembrolizumab versus docetaxel for previously treated, PD-L1-positive, advanced non-small-cell lung cancer (KEYNOTE-010): a randomised controlled trial. Lancet. 2016;387(10027):1540-50

19. Gibbons JD, Chakraborti S. Nonparametric Statistical Inference. 4th ed. New York, Basel: Marcel Dekker, Inc.; 2003. p. 166.

20. Salanti G, Ades AE, loannidis JP. Graphical methods and numerical summaries for presenting results from multiple-treatment meta-analysis: an overview and tutorial. J Clin Epidemiol. 2011;64:163-71.

21. Kibret T, Richer D, Beyene J. Bias in identification of the best treatment in a Bayesian network meta-analysis for binary outcome: a simulation study. Clin Epidemiol. 2014;6:451-60.

22. Rucker G, Schwarzer G. Ranking treatments in frequentist network metaanalysis works without resampling methods. BMC Med Res Methodol. 2015; 15(58):1-9.

23. Borman I. Digitizelt. 2003. http://www.digitizeit.de. Accessed 2 Oct 2014.

24. Guyot P, Ades AE, Ouwens MJ, Welton NJ. Enhanced secondary analysis of survival data: reconstructing the data from published Kaplan-Meier survival curves. BMC Med Res Methodol. 2012;12:9.

25. Grambsch P, Therneau T. Proportional hazards tests and diagnostics based on weighted residuals. Biometrika. 1994;81:515-26.

26. Higgins JPT, Green S, editors. Cochrane handbook for systematic reviews of interventions, version 5.1.0. 2011. http://handbook-5-1.cochrane.org/. Accessed 13 Mar 2014

27. Dias S, Welton NJ, Caldwell DM, Ades AE. Checking consistency in mixed treatment comparison meta-analysis. Stat Med. 2010;29:932-44.

28. van Valkenhoef $G$, Dias S, Ades AE, Welton NJ. Automated generation of node-splitting models for assessment of inconsistency in network metaanalysis. Res Synth Meth. 2016;7(1):80-93.

29. Woods BS, Hawkins N, Scott DA. Network meta-analysis on the log-hazard scale, combining count and hazard ratio statistics accounting for multi-arm trials: a tutorial. BMC Med Res Methodol. 2010;10:54.

30. Hackshaw A. A concise guide to clinical trials. Chichester: Wiley; 2009.

31. Owen RK, Tincello DG, Abrams K. Network meta-analysis: development of a three-level hierarchical modeling approach incorporating dose-related constraints. Value Health. 2015;18:116-26.

32. Wang F, Fu S, Zhou Y-B, Zhang X, Zhang X, Xue C, et al. High EGFR copy number predicts benefits from tyrosine kinase inhibitor treatment for nonsmall cell lung cancer patients with wild-type EGFR. J Trans Med. 2013; 11(90):1-10

33. Lim SH, Lee JY, Sun JM, Ahn JS, Park K, Ahn MJ. Comparison of clinical outcomes following gefitinib and erlotinib treatment in non-small-cell lung cancer patients harboring an epidermal growth factor receptor mutation in either exon 19 or 21. J Thorac Oncol. 2014;9:506-11.

34. Sun JM, Lee KH, Kim SW, Lee DH, Min YJ, Yun HJ, et al. Gefitinib versus pemetrexed as second-line treatment in patients with nonsmall cell lung cancer previously treated with platinum-based chemotherapy (KCSG-LU0801): an open-label, phase 3 trial. Cancer. 2012;118(24):6234-42.

35. Urata $Y$, Katakami N, Morita S, Kaji R, Yoshioka H, Seto T, et al. Randomized phase III study comparing gefitinib with erlotinib in patients with previously treated advanced lung adenocarcinoma: WJOG 5108L. J Clin Oncol. 2016:34:1-13.

36. Kubota K, Niho S, Enatsu S, Nambu Y, Nishiwaki Y, Saijo N, et al. Efficacy differences of pemetrexed by histology in pretreated patients with stage IIIB/IV non-small cell lung cancer. J Thorac Oncol. 2009;4(12):1530-6.

37. Scagliotti G, Hanna N, Fossela F, Sugarman K, Blatter J, Peterson P, et al. The differential efficacy of pemetrexed according to NSCLC histology: a review of two phase III studies. Oncologist. 2009;14:253-63.

38. Reck M, Kaiser R, Mellemgaard A, Douillard JY, Orlov S, Krzakowski M, et al. Docetaxel plus nintedanib versus docetaxel plus placebo in patients with previously treated non-small-cell lung cancer (LUME-lung 1): a phase 3 , double-blind, randomised controlled trial. Lancet Oncol. 2014;15(2):143-55.

39. Borghaei H, Paz-Ares L, Horn L, Spigel DR, Steins M, Ready NE, et al. Nivolumab versus docetaxel in advanced nonsquamous non-small-cell lung cancer. N Engl J Med. 2015;373(17):1627-39.

40. Brahmer J, Reckamp KL, Baas P, Crino L, Eberhardt WEE, Poddubskaya E, et al. Nivolumab versus docetaxel in advanced squamous-cell non-small-cell lung cancer. N Engl J Med. 2015;373:123-36.

41. Gelman A, Rubin DB. Inference from iterative simulation using multiple sequences. Stat Sci. 1992;7:457-511.

42. Plummer M. JAGS: a program for analysis of Bayesian graphical models using Gibbs sampling. Proceedings of the Third International Workshop on Distributed Statistical Computing; Vienna; 2003. ISSN 1609-395X. http:// www.r-project.org/conferences/DSC-2003/Proceedings/Plummer.pdf. Accessed 1 May 2014

43. R Development Core Team. $R$ version 3.1.3: a language and environment for statistical computing. Vienna: R Foundation for Statistical Computing; 2015. ISBN 3-900051-07-0. http://CRAN.R-project.org. Accessed 24 Oct 2015

44. Rucker G, Schwarzer G, Krahn U. netmeta: Network meta-analysis with R. R package version 0.4-3. 2014. http://CRAN.R-project.org/package=netmeta. Accessed 1 May 2014

45. van Valkenhoef G, Kuiper J. GeMTC: network meta-analysis using Bayesian methods. R package version 0.7-1. 2014. http://CRAN.R-project.org/package= gemtc. Accessed 1 May 2015.

46. Kawaguchi T, Ando M, Asami K, Okano Y, Fukuda M, Nakagawa H, et al. Randomized phase III trial of erlotinib versus docetaxel as second- or thirdline therapy in patients with advanced non-small-cell lung cancer: Docetaxel and Erlotinib Lung Cancer Trial (DELTA). J Clin Oncol. 2014;32(18): 1902-8.

47. Penrod JR, Korytowsky B, Petrilla A, Wisnivesky JP, Craver C, Salvati M, et al. Survival of U.S. Medicare patients with advanced non-small cell lung cancer by line of therapy. Presented at American Society of Clinical Oncology; Chicago, Illinois, USA; 2014.

48. Fehrenbacher L, Spira A, Ballinger M, Kowanetz M, Vansteenkiste J, Mazieres $J$, et al. Atezolizumab versus docetaxel for patients with previously treated non-small-cell lung cancer (POPLAR): a multicentre, open-label, phase 2 randomised controlled trial. Lancet. 2016;387:1837-46.

49. Aerts JG, Codrington H, Lankheet NA, Burgers S, Biesma B, Dingemans AM, et al. A randomized phase II study comparing erlotinib versus erlotinib with alternating chemotherapy in relapsed non-small-cell lung cancer patients: the NVALT-10 study. Ann Oncol. 2013:24(11):2860-5.

50. Auliac JB, Chouaid C, Greillier L, Monnet I, Le Caer H, Falchero L, et al. Randomized open-label non-comparative multicenter phase II trial of sequential erlotinib and docetaxel versus docetaxel alone in patients with non-small-cell lung cancer after failure of first-line chemotherapy: GFPC 10. 02 study. Lung Cancer. 2014;85(3):415-9.

51. Camps C, Massuti B, Jimenez A, Maestu I, Gomez RG, Isla D, et al. Randomized phase III study of 3-weekly versus weekly docetaxel in pretreated advanced non-small-cell lung cancer: a Spanish lung Cancer group trial. Ann Oncol. 2006;17(3):467-72.

52. Fossella FV, DeVore R, Kerr RN, Crawford J, Natale RR, Dunphy F, et al. Randomized phase III trial of docetaxel versus vinorelbine or ifosfamide in patients with advanced non-small-cell lung cancer previously treated with platinum-containing chemotherapy regimens. The TAX 320 Non-Small Cell Lung Cancer Study Group. J Clin Oncol. 2000;18(12):2354-62.

53. Garassino MC, Martelli O, Broggini M, Farina G, Veronese S, Rulli E, et al. Erlotinib versus docetaxel as second-line treatment of patients with 
advanced non-small-cell lung cancer and wild-type EGFR tumours (TAILOR): a randomised controlled trial. Lancet Oncol. 2013;14(10):981-8.

54. Garon EB, Ciuleanu TE, Arrieta O, Prabhash K, Syrigos KN, Goksel T, et al. Ramucirumab plus docetaxel versus placebo plus docetaxel for second-line treatment of stage IV non-small-cell lung cancer after disease progression on platinum-based therapy (REVEL): a multicentre, double-blind, randomised phase 3 trial. Lancet. 2014;384(9944):665-73.

55. Gervais R, Ducolone A, Breton JL, Braun D, Lebeau B, Vaylet F, et al. Phase II randomised trial comparing docetaxel given every 3 weeks with weekly schedule as second-line therapy in patients with advanced non-small-cell lung cancer (NSCLC). Ann Oncol. 2005;16(1):90-6.

56. Gridelli C, Gallo C, Di Maio M, Barletta E, Illiano A, Maione P, et al. A randomised clinical trial of two docetaxel regimens (weekly vs 3 week) in the second-line treatment of non-small-cell lung cancer. The DISTAL 01 study. Br J Cancer. 2004;91(12):1996-2004.

57. Han JY, Lee SH, Yoo NJ, Hyung LS, Moon YJ, Yun T, et al. A randomized phase II study of gefitinib plus simvastatin versus gefitinib alone in previously treated patients with advanced non-small cell lung cancer. Clin Cancer Res. 2011:17(6):1553-60

58. Hanna N, Shepherd FA, Fossella FV, Pereira JR, De Marinis F, von Pawel J, et al. Randomized phase III trial of pemetrexed versus docetaxel in patients with non-small-cell lung cancer previously treated with chemotherapy. J Clin Oncol. 2004;22(9):1589-97.

59. Hanna NH, Kaiser R, Sullivan RN, Aren OR, Ahn MJ, Tiangco B, et al. LUMELung 2: a multicenter, randomized, double-blind, phase III study of nintedanib plus pemetrexed versus placebo plus pemetrexed in patients with advanced nonsquamous non-small cell lung cancer (NSCLC) after failure of first-line chemotherapy. J Clin Oncol. 2013;31(15_suppl):8034.

60. Hosomi Y, Yoh K, Kasahara K, Yamada K, Takahashi T, Tanaka K, et al. Docetaxel + ramucirumab (DR) versus docetaxel + placebo (D) as secondline treatment for advanced non-small cell lung cancer (NSCLC): a randomized, phase II, double-blind, multicenter trial in Japan. Presented at American Society of Clinical Oncology; Chicago, Illinois, USA. 2015.

61. Juan O, Aparisi F, Sanchez-Hernandez A, Munoz-Langa J, Esquerdo G, Garcia-Sanchez J, et al. Intercalated dosing schedule of erlotinib and docetaxel as a therapeutic strategy to avoid antagonism and optimize its benefits in advanced non-small-cell lung cancer. Clin Lung Cancer. 2015; 16(3):193-9.

62. Karampeazis A, Voutsina A, Souglakos J, Kentepozidis N, Giassas S, Christofillakis C, et al. Pemetrexed versus erlotinib in pretreated patients with advanced non-small cell lung cancer: a Hellenic Oncology Research Group (HORG) randomized phase 3 study. Cancer. 2013;119(15):2754-64.

63. Katakami N, Morita S, Yoshioka H, Seto T, Urata Y, Satouchi M, et al. Randomized phase III study comparing gefitinib (G) with erlotinib (E) in patients (pts) with previously treated advanced long adenocarcinoma (LA): WJOG 5I08L. J Clin Oncol. 2014;32(5).

64. Kim ES, Hirsh V, Socinski MA, Gervais R, Wu Y-L, Watkins CL, et al. Gefitinib versus docetaxel in previously treated non-small-cell-lung cancer (INTEREST): a randomized phase III trial. Lancet. 2008;372:1809-18.

65. Kim YS, Cho EK, Sym SJ, Hong J, Park I, Ahn HK, et al. Randomized phase II study of pemetrexed versus gefitinib in previously treated patients with advanced non-small cell lung cancer. Presented at American Society of Clinical Oncology; Chicago, Illinois, USA. 2014.

66. Lee DH, Lee JS, Kim SW, Rodrigues-Pereira J, Han B, Song XQ, et al. Threearm randomised controlled phase 2 study comparing pemetrexed and erlotinib to either pemetrexed or erlotinib alone as second-line treatment for never-smokers with non-squamous non-small cell lung cancer. Eur J Cancer. 2013;49(15):3111-21.

67. Nishino K, Imamura F, Kumagai T, Katakami N, Hata A, Okuda C, et al. A randomized phase II study of bevacizumab in combination with docetaxel or S-1 in patients with non-squamous non-small-cell lung cancer previously treated with platinum based chemotherapy (HANSHIN oncology group 0110). Lung Cancer. 2015;89:146-53.

68. Quoix E, Lebeau B, Depierre A, Ducolone A, Moro-Sibilot D, Milleron B, et al. Randomised, multicentre phase II study assessing two doses of docetaxel (75 or $100 \mathrm{mg} / \mathrm{m} 2$ ) as second-line monotherapy for non-small-cell lung cancer. Ann Oncol. 2004;15(1):38-44.

69. Schuette W, Nagel S, Blankenburg T, Lautenschlaeger C, Hans K, Schmidt EW, et al. Phase III study of second-line chemotherapy for advanced nonsmall-cell lung cancer with weekly compared with 3-weekly docetaxel. J Clin Oncol. 2005;23(33):8389-95.
70. Shepherd FA, Dancey J, Ramlau R, Mattson K, Gralla R, O'Rourke M, et al. Prospective randomized trial of docetaxel versus best supportive care in patients with non-small-cell lung cancer previously treated with platinumbased chemotherapy. J Clin Oncol. 2000;18(10):2095-103.

71. Sun Y, Wu YL, Zhou CC, Zhang L, Zhang L, Liu XY, et al. Second-line pemetrexed versus docetaxel in Chinese patients with locally advanced or metastatic non-small cell lung cancer: a randomized, open-label study. Lung Cancer. 2013;79(2):143-50.

72. Takeda M, Yamanaka T, Seto T, Hayashi H, Azuma K, Okada M, et al. Bevacizumab beyond disease progression after first-line treatment with bevacizumab plus chemotherapy in advanced nonsquamous non-small cell lung cancer (WJOG 5910L): an open-label, randomized, phase II trial. Presented at American Society of Clinical Oncology; Chicago, Illinois, USA. 2015.

73. Takeda M, Yamanaka T, Seto T, Hayashi H, Azuma K, Okada M, et al. Bevacizumab beyond disease progression after first-line treatment with bevacizumab plus chemotherapy in advanced nonsquamous non-small cell lung cancer (WJOG 5910L): an open-label, randomized, phase II trial. Cancer. 2016;122(7):1050-9.

74. Zhou Q, Cheng Y, Zhao MF, Yang JJ, Yan HH, Zhang L, et al. Final results of CTONG 0806: a phase II trial comparing pemetrexed with gefitinib as second-line treatment of advanced non-squamous NSCLC patients with wild-type EGFR. J Thorac Oncol. 2013;8:S194-5.

75. Zhou Q, Cheng Y, Yang JJ, Zhao MF, Zhang L, Zhang XC, et al. Pemetrexed versus gefitinib as a second-line treatment in advanced nonsquamous nonsmall-cell lung cancer patients harboring wild-type EGFR (CTONG0806): a multicenter randomized trial. Ann Oncol. 2014;25(12):2385-91.

76. Midha A, Dearden S, McCormack R. EGFR mutation incidence in non-smallcell lung cancer of adenocarcinoma histology: a systematic review and global map by ethnicity (mutMapll). Am J Cancer Res. 2015;5(9):2892 911.

77. Boch C, Kollmeier J, Roth A, Stephan-Falkenau S, Misch D, Gruning W, et al. The frequency of EGFR and KRAS mutations in non-small cell lung cancer (NSCLC): routine screening data for central Europe from a cohort study. BM Open. 2013;3:e002560.

\section{Ready to submit your research? Choose BMC and benefit from:}

- fast, convenient online submission

- thorough peer review by experienced researchers in your field

- rapid publication on acceptance

- support for research data, including large and complex data types

- gold Open Access which fosters wider collaboration and increased citations

- maximum visibility for your research: over $100 \mathrm{M}$ website views per year

At $\mathrm{BMC}$, research is always in progress.

Learn more biomedcentral.com/submissions 